\title{
Structure and Resolution of Systemic Problems
}

\author{
Janos Korn \\ Department of Design Engineering and Mathematics, Faculty of Science and Technology, Middlesex University, UK
}

Received February 5, 2020; Revised April 24, 2020; Accepted May 3, 2020

Copyright $\subseteq 2020$ by authors, all rights reserved. Authors agree that this article remains permanently open access under the terms of the Creative Commons Attribution License 4.0 International License

\begin{abstract}
The dichotomy of 'production' and 'product' or the means of progression from one 'equilibrium state' to another is suggested. This phenomenon runs throughout both the natural and artificial words. As shown in Figure 1, nearly all human intellectual endeavour has been concerned with understanding the notion of product which is closer to immediate human interests. Humanity has achieved producing products, physical, intellectual or artefacts, and works of arts of ever-increasing complexity because its ability to construct production systems or structures is innate. Organised approaches to understanding the workings of structures or systems have only been attempted during and after the $2^{\text {nd }} \mathrm{WW}$ when control theory was developed followed by more 'general systems thinking' initiated by von Bertalanffy beginning with the 1950's. These approaches, although inspiring and ground breaking, lack the fundamentals of the structural view of the world, fragmented, mostly speculative with superficial effort to help problem solving or design thinking and do not fit into branches of accepted knowledge and teaching schemes. The purpose of this study is to address these issues using the methodology of conventional science with 'systemic content'. The study has produced a generalised structure of problem solving for the resolution of systemic problems which can be expressed in 'testable', operational form through the symbolism of 'linguistic modelling'. The suggested criteria reach out to other symbolisms to filter out those which do not satisfy this condition. The symbolism of linguistic modelling is amenable to computing when software is available, supported by applications and passed the test of debate.
\end{abstract}

Keywords New Science of Systems, Problem Structuring, Linguistic Modelling

\section{Introduction}

The term 'system' has been used for millennia by people of all background in a kind of instinctive, desultory way to refer to the structural properties of a part of the world which appears complex. It was in the $2^{\text {nd }} \mathrm{WW}$ that theoretical approaches with systemic or structural features such as control theory and operational research were developed (Brown, Campbell, 1948, Blackett, 1948). These were intended to deal with 'problematic issues' like gun control for shooting at moving targets and determining the optimum size of convoys of ships to avoid enemy submarines.

These approaches were based on mathematical modelling following the tradition of conventional science, there was no other comparable approach. It was Bertalanffy in the 1950's who drew attention to the generality of the notion of 'system' (Bertalanffy, 1950). This intellectual direction had taken up on a large scale to the present day, by and large in a speculative direction and has led to fragmentation of a basically indivisible, empirical view of the structural nature of the world (Korn, 2019). Currently, however, the usefulness of this direction is beginning to be questioned. The approach, a paradigm change, which is suggested here can address these questions.

People habitually make hypothetical statements about parts of the world. Conventional science of physics adopted this but demands that such statements be general and testable by experiment or observation (Popper, 1972).

The $1^{\text {st }}$ General Principle of Systems says (Korn, 2018): 'Parts of the world are universally seen as structures or systems at various levels of 'complexity' of interrelated concrete, abstract, symbolic, imaginary [ideas, centaur] and emotive entities'. However, ---

1. Conventional science deals with selected aspects of an entity seen as a whole using mathematical models of quantifiable variables and properties,

2. Current methods of 'systems thinking' are speculative and fragmented with ill defined concepts (Beer, 1979, Checkland, 1982, Jackson, 2000),

3. The $1^{\text {st }}$ Principle requires an equally universally applicable approach called here the 'New Science of Systems' which follows the methodology of 
conventional science but with systemic content so as to aid problem solving. It consists of three principles and the symbolic structure of model of 'processed natural language' (Korn, 2009, 2018, 2019). The aim of the approach is to capture:

The fundamental features of the empirical, universal, systemic or structural, view of parts of the world which is to lead to results at operational level for the resolution of 'problematic issues' manifested by yielding 'outcomes of scenarios' and is introduced here to be debated.

Natural language, which is the primary symbolism, is general enough to deal with the generality of systemic view but in its every day usage is much too rich in expressive power, rich in linguistic complexities, innuendoes and has a reasoning power limited to formal logic (Copy, 1978). In order to represent, to reason methodically, to explicitly show outcomes of static or dynamic scenarios and to engage in their design, natural language description is transformed into a computable reasoning scheme by 'linguistic modelling' shown diagrammatically in Figure 9. It is an exploration method for existence of outcomes of the initial natural language description of scenarios that can be supplemented by mathematics and uncertainty theory. It incorporates conventional science at the object level resulting in a 'creative, scientific enterprise' (Lewin, 1981).

To achieve this kind of aim, an approach must be 'scientific' or come up with 'testable' outcomes. Criteria for judging whether an approach fulfils this condition are proposed which enable current methods of 'systems thinking' or any other method to be evaluated from this point of view.

\section{Paradigm Changes in the History of Ideas}

Human intellectual endeavour has taken place along 'paradigm changes' over millennia (Kuhn, 1996). Figure 1. is an attempt to place the current paradigm changes in 'systems thinking' in a recent, historical context. It points out that such endeavour has been directed at 'problem solving' which is the all-pervasive activity of all living things. The alternative is extinction (Korn, 2018).

Perhaps the most significant paradigm change came about by the development of 'conventional science of physics' in the Renaissance, the $1^{\text {st }}$ paradigm change in Figure 1., along the line of 'qualitative, quantitative' interest where nearly all human, intellectual endeavour has been going on. Lack of theoretical activity along the 'structural interest' branch in Figure 1. or 'problem solving' as referred to in the 'Introduction', has been compensated for by the practice of this activity being innate in the living.

The $2^{\text {nd }}$ paradigm change is seen to have taken place as indicated after contour 10 into systemic awareness as currently practiced in contours $11,12,13$. The $3^{\text {rd }}$ paradigm change is proposed to take place using the "New Science of Systems' in contour 14 . 


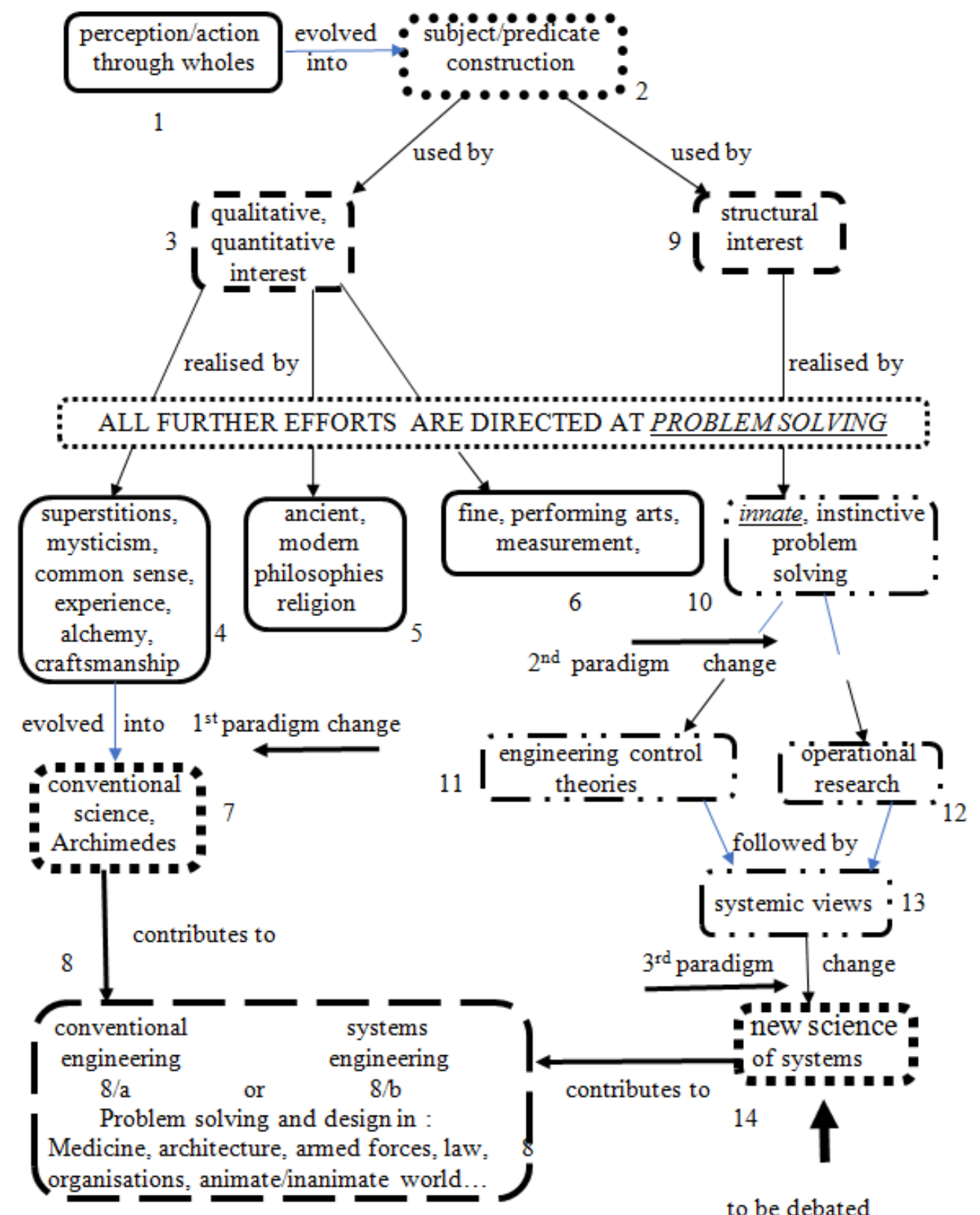

Figure 1. Diagram of constituents of human intellectual endeavour 


\section{Evolutionary View of the World}

We distinguish the following domains of experience of parts of the WORLD, an empirical view:

1. Natural, inanimate world in 'static, dynamic state':

Earthquake $\rightarrow$ Rocks, mountains

Volcanoes $\rightarrow$ Lava

Tornado $\rightarrow$ Wind [where the 'arrow' means 'produces']

2. Natural, animate world in 'static, dynamic state':

Micro and macro biological organisms, plants, animals and human beings at biological level $\rightarrow$ Survival, waste

3. Artificial, inanimate world in 'static, dynamic state':

Products and components in purposive configuration such as control and computer systems, robots $\rightarrow$ Artefacts, devices, compounds, direction control

4. Artificial, animate world in 'static, dynamic state':

Arrangements of purposive configurations from selected parts of one or more domains described above at the social level like a pride of lions, beehive, a political party, social systems, manufacturing and distributing organisations or any feasible combination of elements from different domains like a boy throwing a rock at a nearby fish or people travelling in an airplane to holiday - Survival, social groups, control systems with living components, vast variety of physical and intellectual artefacts, physical and intellectual properties [speed, clever].

Accordingly, there is a huge variety and diversity of 'existence' and of intense 'activity' going on in identifiable parts of the world by chance or in accordance with purpose. The core theme that runs throughout the domains is 'Producers and products'. Further order can be discerned in existence and activities in parts of the inanimate and animate words by searching for:

A. 'Identities and regularities [how domains and classifications are created],

B. 'Explanations and predictions' [why a state as it is and why an event has occurred or 'reasons' or 'causes'], and

C. 'Purposes' [how problems are solved).

Over the past and at present people in the course of their daily life, craftsmen, artists, scientists, engineers, professionals have been trying to create symbolic structures based on 'sensory input' of aspects of the empirical world and using creative imagination by the brain/mind apparatus. Their objective is to create 'reasoning schemes' of all kinds as indicated in Figure 1., for resolving problems arising from points A., B. and C.

Based on previous work, the intention of this paper is to introduce a 'New Science of Systems' offered as a means of resolution of 'problematic issues' in point $\mathbf{C}$. involving point $\mathbf{B}$., in a way which is seen to be closer to the ideal of 'empirical theory or symbolic structure' and as such reducing the perceived deficiencies in current 'systems thinking'. Criteria are suggested towards judging how close a symbolic structure is to what is considered the ideal (Korn, 2019).

\section{View of the Current State of Systems Thinking}

Any part of the world is seen as 'systemic or structural [static or dynamic] entity'. This view is pervasive, empirical, hierarchical or 'nested' and indivisible, although not unique (Korn, 2018). This kind of formulation was recognised by von Bertalanffy (Bertalanffy, 1950) who proposed the idea of 'General Systems Theory' as its expression. However, this idea has remained on the speculative and fragmented level over the last 70 years or so as referred to in contours 10, 11, 12, 13 of Figure 1. Current systems thinking is characterised by features:

1. The expression of von Bertalanffy's idea in symbolic form has been attempted in a number of ways but no acceptable result has materialised, and the search continues (Klir, 1969, Rousseau, 2017),

Point 1. has not succeeded so far,

2. In parallel, a multiplicity of approaches has emerged to find symbolic expressions of aspects of systems thinking. They can be characterised by having ill defined concepts, with practically no roots in existing knowledge, difficult to teach etc. such as VSM, SSM, System Dynamics, Critical system heuristics and so on (Jackson, 2000),

Point 2. with its variety of methods has led to fragmentation against the idea of generality of the systemic or structural view, its instances can be seen unsatisfactory and have led to lack of clarity [what is understood by the terms 'system' or 'systems thinking' is still debated],

3. People have been engaged in speculative, stimulating discussions, for example, autopoiesis and relational science (Maturana, Varela, 1980, Kineman, 2011),

Point 3. is not aimed at producing an empirical theory of systems or structures,

4. There does not appear to be a generally acceptable method of problem solving or structuring of problems which is the central issue in activities of living things, the alternative is extinction,

Point 4. appears to be still searched for (Korn, 2019),

5. Emergence of control theory and operational research during the $2^{\text {nd }} \mathrm{WW}$ with problems outside the realm of conventional disciplines and the science of physics (Nise, 2008), 
Point 5. has a number of unsatisfactory features (Korn, 2009,2012 ) and lack of a concept unifying these disciplines,

6. Emergence of a number of organisations such as ISSS, UKSS, BS Laboratory, OR Society with interest in different aspects of system thinking,

Point 6. reflects the multiplicity of ideas against the single concept of 'system or structure'.

These points constitute a summary of views of the current state of systems thinking and is regarded as the 'problematic issue' which the ideas that follow are intended to alleviate. The ideas are along the lines suggested by von Bertalanffy but aiming for their expression in more concrete terms (Korn, 2018, 2019).

\section{Achievements of Living Things and Problem Solving}

There are two ways a symbolism or a model for description and communication of aspects of a part of the world or empirical object following a 'thought', can be constructed:

1. From 'Sense input' and its interpretation leading to abstract terms, or

2. 'Imagination'.

Furthermore, the basic form of the symbolism that can carry complete meaning or thought is the 'subject predicate' form as indicated in contour 2 in Figure 1., the grammatical elements of which can be qualified by (Burton, 1984):

QUALITATIVE/QUANTITATIVE properties ---

These elements are,

A. Subject: Stands for designation of a concrete, abstract, symbolic, imaginary [centaur] and emotive object for locating the interest of the 'producer of thought' in a part of the world, and/or

B. Predicate: The designations or 'cases' and the verbs which connect $\mathrm{A}$. and $\mathrm{B}$.

For example: 'The [clever] John is [smart]', 'The [hungry] John went [out to eat] to a [cheap] restaurant', 'The car has a [speed of $35 \mathrm{~km} / \mathrm{h}]$ '.

Qualitative/quantitative properties [adjectives and adverbs] make a sentence and sentence elements specific or turn a 'context - free' sentence into 'context - dependent' which can be tested against experience (Popper, 1972).

Alternatively, the 'subject - predicate' form can be constructed leading to

RELATIONAL properties which consist of

A. Subject: Designates a concrete, abstract, symbolic, imaginary or emotive object, and

B. Predicate: Uses 'stative' or 'dynamic' verb to indicate static or dynamic state of the 'subject' and the rest of

the predicate of the sentence or the description of a scenario.

For example: 'John [floats] on the water', 'John [jumps] into the water'.

Descriptions A. and B. together called the 'systemic or structural property' which expresses the 'relationship' between the 'subject' of a sentence and the rest of the predicate created by the 'verb'. Thinking in terms of systemic properties of an object or a scenario is called SYSTEMS THINKING.

Practically the WHOLE of human intellectual and material achievements have been expressed using 'qualitative/quantitative' properties. A possible reason for this is:

AMBITIONS or objectives of living things like: Survival, convenience, power, influence, improvements in physical and mental well being [own and of others], feelings, emotions, desires, wishes etc. are accessible by means of the 'senses' and instruments through qualitative/quantitative properties. These are then interpreted by the brain/mind and can be formulated in terms of suitable symbolism such as writing, mathematics, painting. Any ambition is realised by means of ACHIEVEMENT.

For

example,

Ambition
To survive
To have
convenience
To have power
To have mental
well being

where the words in italic designate the achievement and the dynamic verbs indicate action.

There is a relation between ambitions and achievements. Ambitions vary in 'difficulties' and complexities which can be formulated in terms of 'properties'. They drive the complexity of the corresponding achievements which requires the corresponding complexity of the 'algorithm' to carry them out (Korn, 2009, 2018].

For example, we have: Ambition = 'Man wants to kill the enemy who is $1 \mathrm{~m}$ away'

Process of achievement $=$ 'Man uses a stick'

= 'Man wants to kill the enemy who is $50 \mathrm{~m}$ away'

$=$ 'Man uses a bow and arrow'

= 'Man wants to kill the enemy who is 500 m away'

$=$ 'Man uses a gun'.

Expressing the 'difficulties' of ambitions in terms of 'properties' enables their 'evaluation' or assessment. In this example we note that as the difficulty of ambition increases so does the complexity of the product or 
achievement required for its accomplishment.

When an ambition such as 'building a house' is expressed by means of an architect's drawing we can gauge the 'difficulty' and complexity of arrangement of properties required for carrying out the ambition and the subsequent complexity of the algorithm of the 'process of achievement'.

Consideration of the notion of ACHIEVEMENT in its widest sense can lead to:

i. The concept of achievement is identified with the notion of product or artefact,

ii. The function of the 'product' is to change the state of an 'object carrying a problematic issue, designated $O P I^{\prime}$ which arises in a 'problematic situation' or 'story',

iii. The 'product' can do this by being manufactured, assembled and delivered by a 'producer' to a 'notional' or 'actual' market, iv. The 'producer' operates according to a plan as directed by a 'brain/mind',

v. The 'brain/mind' directs the 'producer' so as to result in a 'product' that can change the state of 'OPI' to lead to satisfaction of expectation of another object referred to as 'User/utiliser'.

We are dealing with problem solving operating as a 'purposive system' the structure of which is shown in Figure 2.

For example, the story: 'People in a village would like to cross the river more easily than at present' in which the 'uncrossed river' is IS of 'OPI', the 'not yet existing means of crossing' is the 'product' to be produced by 'producers' and the 'people' are the 'User/utiliser' to be satisfied. The 'requirements' of OPI should be met by 'specification' of the 'product' as shown in Figure 3. and the 'expectations' or 'need' of people should be satisfied by the 'river crossed [FS of OPI] by the product'.

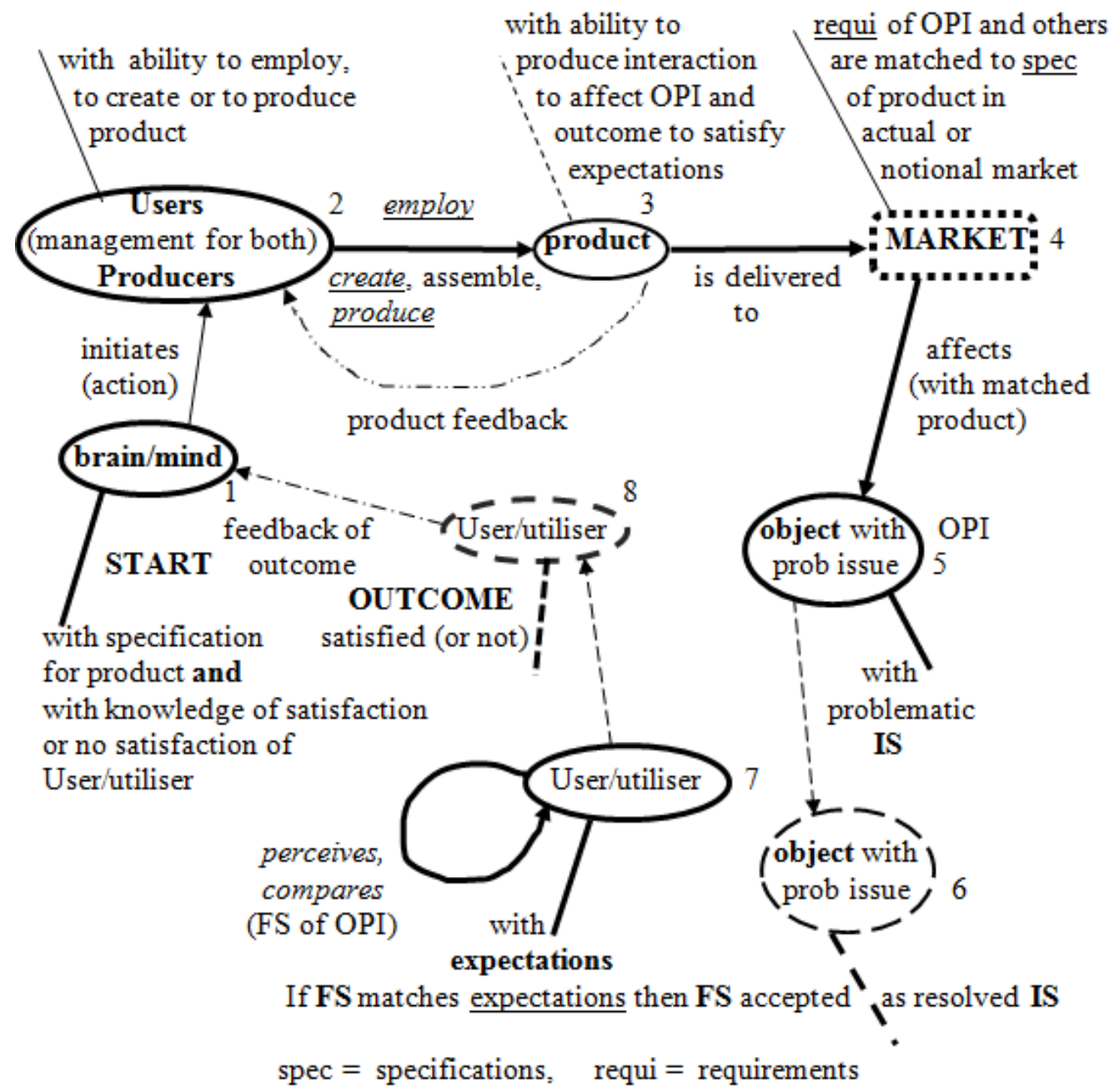

Figure 2. Diagram of problem structuring scheme 


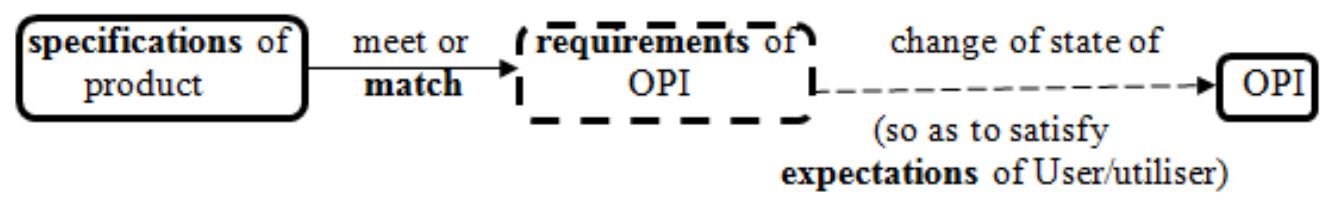

Figure 3. Definition of 'market'

which takes place at a 'market' otherwise there is no consistent, change of state into a final state [FS] which is to satisfy expectations of User/utiliser

Another example, the story 'The public [User/utiliser] enjoy hearing [OPI] the tune of a piece of music [product], they do not usually care about how the composer created the symbolism of musical notation and reproduced by the orchestra' [producer].

The diagram of 'problem solving' in Figure 2. is suggested to act as a problem structuring method. It can help in resolving 'problematic issues' in 'simple' as well as in 'wicked problems' (Rittel, Webber, 1973):

By searching for the meaning of a term in the 'story language' of a 'problematic situation' described as a 'story' which is equivalent to or contained in a term in the 'model language' of Figure 2. (Saeed, 1998). This operation can then lead to development into a more abstract 'model' like a mathematical model or linguistic model.

Figure 2. raises two questions:

1. How it has been used by professional people like engineers, doctors, politicians, systems engineers or by people in their everyday life, animals and plants over the past and present times, and

2. How it can be implemented in operational form.

Answer to the $1^{\text {st }}$ question: Professional people use parts of the scheme in Figure 2. For example, a doctor on hearing the symptoms of a patient, the 'problematic issue', OPI, prescribes a medicine which is the achievement or product. Patient is also the User/utiliser. The doctor is engaged in a part of trouble shooting.

Answer to the $2^{\text {nd }}$ question: Is given in this and other writing (Korn, 2009, 2016, 2018, 2019] and shown here by an example.

\section{Remarks}

1. Problem solving is a part of evolution which is directed from an initial state of equilibrium of a 'problematic scenario', an aspect of which found unsatisfactory or liable to change to a final or new state of equilibrium or 'resolved scenario' which can be more complex than the initial state of equilibrium. The transformation from an initial state of equilibrium to a final state is carried out by action of a 'physical system' or 'structure', driven by a physical effect like gravity or mental state or an idea or an objective like 'wanting to have a holiday' in case of human beings.
2. Resolution of a 'problematic scenario' or problem solving is a universal activity in the living sphere, the alternative is extinction. The scheme of problem solving is executed by the 'systems engineer' or by anybody in the course of everyday life including animals and plants in a restricted sense, and consists of two parts:

First part: The perception by a person or a living thing or an 'initiator' by inspiration, instinct, intuition, imagination or experience of:

An object with the 'problematic issue', OPI, through its undesirable IS [initial state] manifested by properties impinging on the senses and its proposed, consistent FS [final state] so as to satisfy the expectations of a User/utiliser as shown in Figure 2.,

The notional or actual Market where matching of FS to expectation of User/utiliser takes place, is indicated in Figure 3.

Second part: The executive part or creation of 'prototype' or the apparatus or structure ['brain/mind', the organiser of 'producer' which is the maker of 'product'] intended for alleviating the 'problematic issue' carried by OPI and to lead to satisfaction of User/utiliser as diagrammed in Figure 2. This is the part usually associated with the term 'design thinking'.

3. Figure 2. is a diagrammatic representation of the following systems as particular cases:

A. Utilising systems which are recognised by their use of 'existing products'

B. Producing systems which are recognised by their activity of manufacturing, assembling and delivering 'products'

C. Trouble shooting systems exist through perception of a 'OPI, 5-6' through 'symptoms' manifested by a breakdown [of a car], deficiency [of vitamins], disease [of heart] and seeking 'producers, 2' to 'restore fuel supply', 'supply of vitamins' etc. to eliminate symptoms so as to satisfy 'User/utiliser, $7-8$.

D. Inanimate systems which are recognised by the presence of 'producers, 2' (with no management) producing 'product, 3' and possibly affecting a 'User/utiliser, 7-8' such as a volcano can affect people living nearby.

Depending on the absence or presence of expressions in the story or narrative, it is possible to judge which system, A., B., C. or D. the analyser, observer or designer is dealing 
with. Depending on this, terms in Figure 2. will be absent.

All activities are directed towards progressing from one state of equilibrium to another state which can be more complex than the previous (Korn, 2012).

4. Figure 2. is the 'universal form of a scenario' expressed in abstract, 'model language'. However, a particular, 'problematic scenario' is described in terms of 'story language'. In order to lead into the reasoning scheme of 'linguistic modelling' the 'story language' needs to be transformed into 'model language'.

The question of transformation of 'model into story language and vice versa' is considered in detail in section 'Criteria of a symbolic structure to be 'scientific'.

\section{Operational form of figure 2}

This section consists of two parts: The $1^{\text {st }}$ part introduces the 'elementary constituents' of linguistic modelling and the $2^{\text {nd }}$ part shows an example of operational form as a particular case of the scheme in Figure 2. (Korn, 2009).

\section{Elementary Constituents of Linguistic Modelling}

Scenarios described as 'stories' or 'narratives' in natural language, the 'primary model' or 'story language' are converted into 'model language' of Figure 2., the problem solving scheme, which identifies the functional objects or agents in a scenario (Korn, 2009). The scheme of Figure 2. can then be expanded into a reasoning structure by linguistic modelling in particular cases using elementary constituents following the procedure as shown in Figure 9. (Korn, 2009, 2013, 2016).

Any structure, concrete, abstract or symbolic, perceived as a whole is constructed from 'elementary constituents' prevailing at the local level of complexity according to the $1^{\text {st }}$ general principle of systems (Korn, 2018). Molecules, electrical networks, a herd of cattle, a squad of soldiers, a car repair workshop are regarded as organised wholes of elementary constituents of atoms, network elements (Korn, 2012), bricks, cows, soldiers, officer, boss, foremen, craftsmen, respectively. Discovery of elementary constituents like 'air, fire, water and earth' or instances of the periodic table of elements, has been a preoccupation of thinkers for a long time (Levene, 2010).

The elementary constituents of linguistic modelling are '1- and 2 - place sentences' (Korn, 2009) which are reintroduced here because of the introduction of 'decision making' as part of 'driving properties' and interactions qualified by 'changes from IS to FS' as adverbial qualifiers which become part of acquired properties. They also serve as an introduction to linguistic modelling.

The 'semantic diagram' of a 2 - place sentence: 'The householder needed grey paint which he obtained from the local store' is shown in Figure 4. With reference to Figure 4., action or simulation is initiated at time $=0$ when the 'difference between the householder needs to have paint' and 'paint is to be obtained from the local store' is formulated.

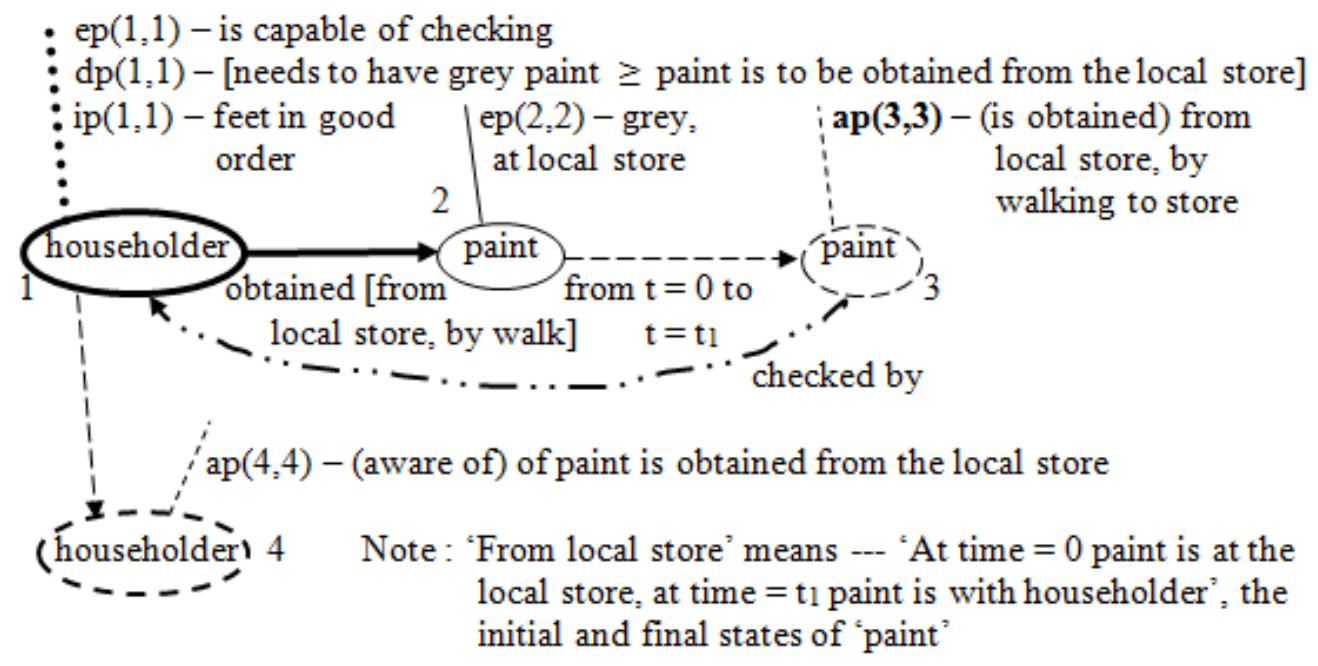

Figure 4. Semantic diagram of a ' 2 - place sentence' with decision 
Before constructing Figure 4. matching 'model to story language' is given by:

Model language Story language

Brain/mind, 1 --- householder (identifies 'problematic issue' - he has no paint and specifies kind of paint)

OPI, 5-6 --- householder (IS - he has no paint, FS - he has paint)

User/utiliser, 7-8 --- householder (expects to have paint as specified)

Product, 3 --- [grey] paint

Management, users, 2 --- householder obtained 'paint' (from local store)

which is a 'Utilising system' with 'notional market'.

From Figure 4. the causal chain is 4, 1, 3, 2, 1 which starts at an object which no longer changes, contour 4 , and proceeds against the arrowed dotted lines designating changes of state. Hence, the predicate logic statements in symbolic form here without 'uncertainties' and 'graded adjectives' and explained in (Durkin, 1994, Korn, 2009), are

$\operatorname{dp}(1,1) \wedge \quad \operatorname{ip}(1,1) \rightarrow \operatorname{in}(1,2,[\operatorname{adv}(1,2)]) \quad$ where $\operatorname{in}(1,2,[\operatorname{adv}(1,2)]$ is qualified by

$\operatorname{in}(1,2,[\operatorname{adv}, 1,2]) \wedge \mathrm{ep}(2,2) \rightarrow \operatorname{ap}(3,3)$ the initial conditions

$\operatorname{ap}(3,3) \rightarrow \operatorname{in}(3,1)$

$\operatorname{in}(3,1) \wedge \mathrm{ep}(1,1) \rightarrow \mathrm{ap}(4,4)$

in which the additional term ' $\mathrm{ep}(1,1)$ ' is to express a property of the affected object 'householder' required by the formalism. In words:

If 'The householder needs to have paint' and 'paint is to be obtained from the local store" and 'the householder's feet are in good order' then 'householder obtained paint from the local store by walking to the store'

If 'the householder obtained paint from the local store by walking to the store' and 'the paint is grey' then 'paint is obtained from the local store by walking'

If 'paint is obtained from the local store by walking' then 'paint is obtained from the local store is checked by the householder'

If 'paint is obtained from the local store is checked by the householder' and 'householder is capable of checking' then 'householder is aware of paint is obtained from the local store'

We note that successful accomplishment of 'paint is obtained from the local store $(a p(3,3))$ ' depends on the 'colour of the paint' which must be specified by the 'householder' in this case.

A 'product' can be expressed as a set of 'ordered pairs', each of which is created by change of state as part of an elementary constituent (Korn, 2009, 2016). The ordered pair at object 3 is

$$
\mathrm{n}_{3,10}=\text { [grey]paint(obtained[by walking])fromstore[local] }
$$

which is represented as a 'linguistic network' in Figure 5. and constitutes the elementary constituents of which a product is constructed.

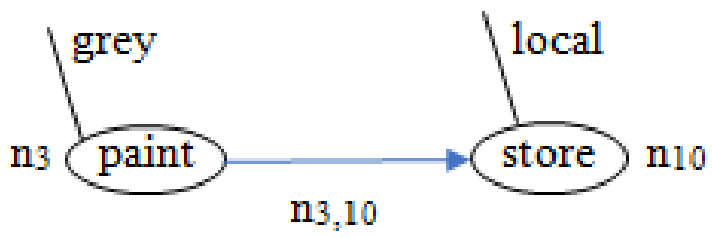

Figure 5. Linguistic network of ordered pair

The second kind of elementary constituent is the ' 1 place sentence' such as 'The well-equipped enemy wanted to occupy the trenches, so it advanced towards them'. The semantic diagram is shown in Figure 6. The derivation of logic sequence is the same as for a ' 2 - place sentence', its verbal equivalent is given as follows:

If 'there is a difference between 'the enemy wanted to occupy the trenches' and 'the enemy is advanced to the trenches" then 'the enemy advanced to the trenches'

If 'the enemy advanced to the trenches' and 'the enemy is well equipped and capable of perception' then 'the enemy is advanced to the trenches'

If 'the enemy is advanced to the trenches' then 'the (position of) enemy is checked by the enemy'

If 'the (position of) enemy is checked by the enemy' then 'the enemy is aware of being in the trenches'

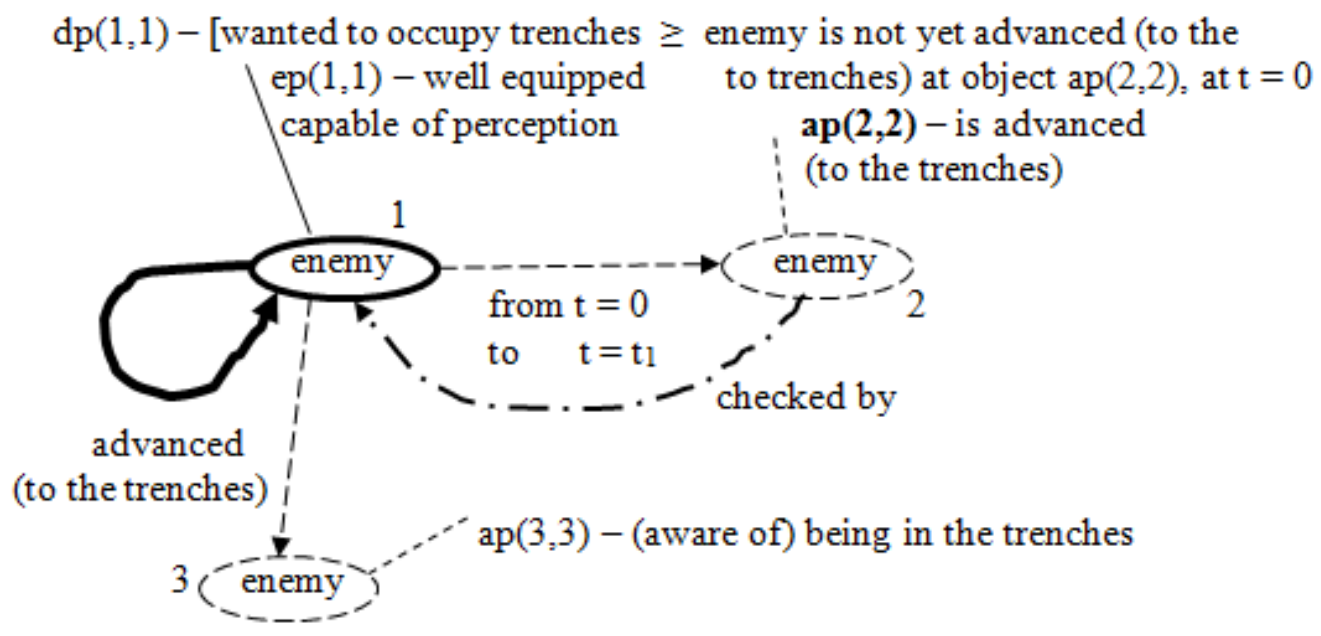

Figure 6. Semantic diagram of a ' 1 - place sentence' with feedback 


\section{Operational form of Figure 2}

This is shown by means of an example for how to use 'linguistic modelling of scenarios' which is the symbolic part of the 'New Science of Systems' (Korn, 2018) and expresses the scheme in Figure 2. in operational form. The following is an example of how this can be done.

\section{Application of natural language}

The story is as follows: 'A householder having inspected his garden fence, concluded that it needed painting. He decided to do the job himself so as to ensure that it will enhance the visual appearance of the property'.

2. Identification of story terms with model terms in Figure 2.

OPI $[5,6]$--- garden fence [carries the initial (IS) and final states (FS) to affect the expectations of User/utiliser [7]]

Product [3] --- brush + other objects [produces interaction to cause change of state $[5,6]]$

Man/prod [2] --- householder using his hands

Initiator, Brain/mind [1] --- householder [discovers garden fence needs to be painted]

User/utiliser [7,8] --- householder [the human object to be satisfied by FS of OPI $[5,6]]$

\section{Conversion of story into operational model}

Elucidation of elementary constituents, construction of complex structures in relationships for comparison with Figure 2. and testing it including the prototype if required.

A. Homogeneous language of context - free, $1-$ and $2-$ place sentences

These sentences define the structure or topology or the algorithm of the scenario. Without this we cannot construct the 'semantic diagram' of the scenario. In this case they are implied by the story.

1. 1. Householder obtained paint

2. 2. Householder prepared brush

3. 3. Householder painted fence

\section{B. Semantic diagram}

Shown completed in Figure 7. and demonstrates the 'structure' of the scenario and acts as an aid in pointing out the qualifiers or 'properties' which are demanded by the symbolism of the diagram (dp, ep etc, Korn, 2009). The required qualifiers are obtained from the 'story' or invented to satisfy the rules of linguistic modelling.

\section{Adjectival qualifiers with grading}

Grading can be assigned to qualifiers to vary their effect on the performance of the object which they qualify. The technique is explained in detail in (Korn, 2009).

$\mathrm{dp}(1,1)$ - householder having inspected property, wants to do the job [strongly, just] (in keeping with the overall decoration scheme of the property so as to enhance the visual appearance of the property)

ip $(1,1)$ - householder's hands are in good order

$\mathrm{ep}(2,2)$ - paint is grey

ep $(5,5)$ - quality of brush [hard, soft]

ep $(8,8)$ - rough surface

D. Interactions with adverbial qualifiers

in $(1,2)$ - householder obtained paint [from local store] in $(4,5)$ - householder prepared brush [for painting] in $(7,8)$ - householder painted the fence [by hand] bearing in mind ' $\mathrm{dp}(1,1)$ ' selected ' $\mathrm{ep}(2,2)$ '

\section{E. Logic sequences/topology of scenario}

Causal chains from Figure 4. : 1. 9, 8, 7, 4, 6, 5, 4, 1, 3, 2, 12. 11,10

For causal chain 1 .

$\mathrm{dp}(1,1) \wedge \mathrm{ip}(1,1) \rightarrow \mathrm{in}(1,2,[\mathrm{adv}, 1,2])$ delivering precondition for

$\operatorname{in}(1,2,[\operatorname{adv}, 1,2]) \wedge \mathrm{ep}(2,2) \rightarrow \operatorname{ap}(3,3)$ application of 'product'

ap $(3,3) \rightarrow$ in $(3,1)$

in $(3,1) \rightarrow$ ap $(4,4)$

$\operatorname{ap}(4,4) \rightarrow \operatorname{in}(4,5,[\operatorname{adv}, 4,5])$ delivering precondition for $\operatorname{in}(4,5,[\operatorname{adv}, 4,5]) \wedge \operatorname{ep}(5,5) \rightarrow \operatorname{ap}(6,6)$ application of 'product'

ap $(6,6) \rightarrow \operatorname{in}(6,4)$

in $(6,4) \rightarrow$ ap $(7,7)$

$\operatorname{ap}(7,7) \rightarrow \operatorname{in}(7,8,[\operatorname{adv}, 7,8])$

$\operatorname{in}(7,8,[\operatorname{adv}, 7,8]) \wedge \mathrm{ep}(8,8) \rightarrow \operatorname{ap}(9,9)$

For causal chain 2 :

$\mathrm{dp}(10,10) \rightarrow \mathrm{in}(10,10)$

in $(10,10) \rightarrow$ ap $(11,11)$ User/utiliser

START activities at object 1. initiated by 'dp' property: 


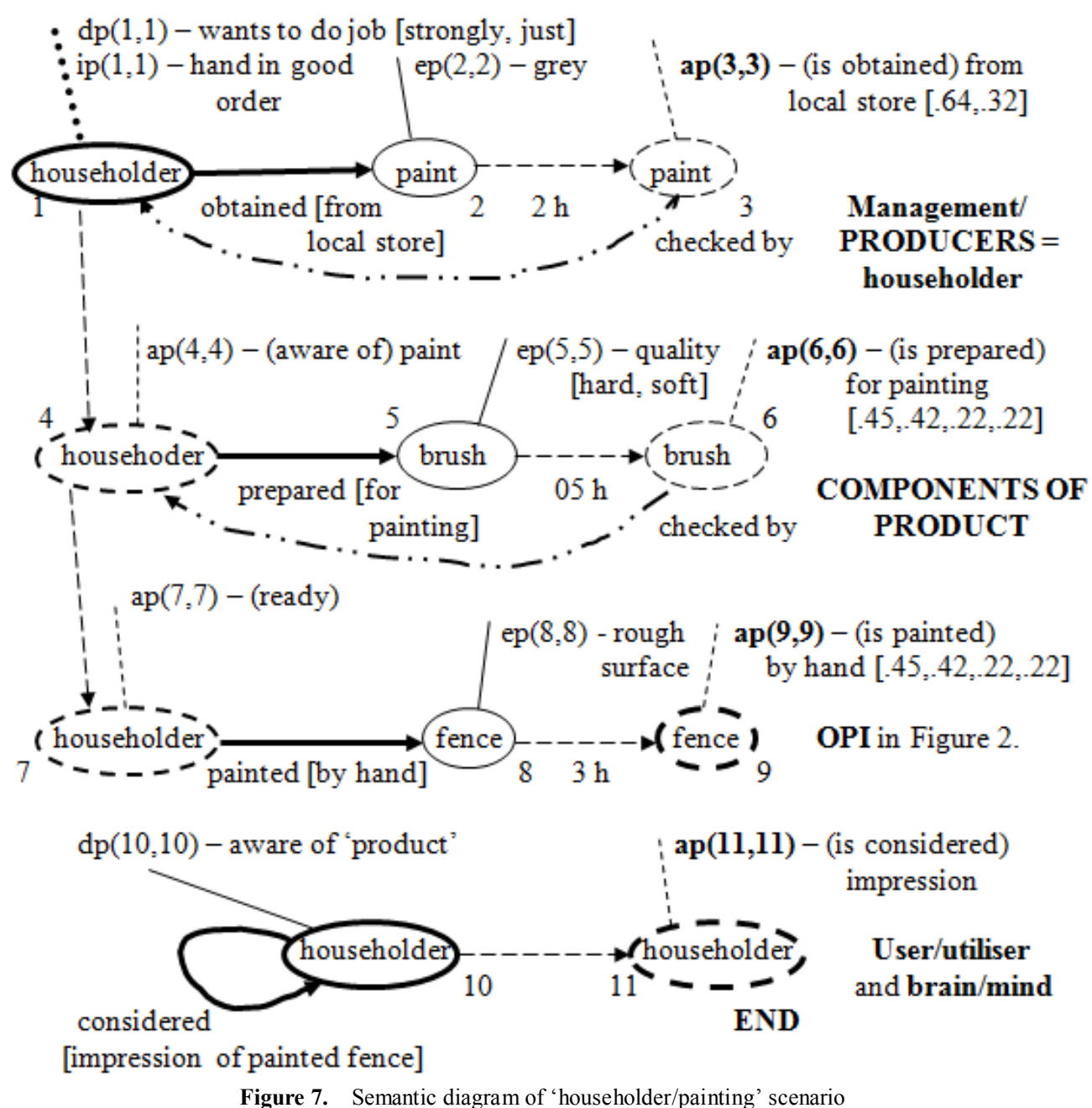

F. Logic sequences with graded qualifiers/data for certainty factors [cf]

For causal chain 1.

dp(hhol,1,1,(job(strong,90/0.8,just,40/0.4)))

$\mathrm{ip}($ hhol,1,1,(hand(good,90/0.9)) $) \rightarrow$

(cf of rule, 0.8 ) in (obt, hhol, 1, paint, 2, (from (store)) $(0.64,0.32)$

in which to each grade we assign two numbers which lead to certainty factor, cf. The first number between - 100 and +100 designated by the symbol ' $\mathrm{a}_{\mathrm{i}}$ ', is intended to express the 'significance, importance or relevance of the grade' as part of a property as far as the 'outcome in the consequent of the conditional' is concerned. The second number between -1 and +1 designated by the symbol ' $b_{i}$ ', is intended as a 'measure of belief or confidence in certainty' as shown in Fig.4.3. in (Korn, 2009) that an object has a particular grade of a particular property (Durkin, 1994).

The resultant ' $\mathrm{cf}$ ' of the consequent is obtained from

(cf of rule) $\mathrm{x} \min \left(\mathrm{cf}_{\mathrm{dp}}, \mathrm{cf}_{\mathrm{ip}}\right)=0.8 \times((\min (0.8,0.9)$, $\min (0.4,0.9))=.64, .32)$ (Durkin, 1994).

The assignment of certainty factors is based on subjective judgement and follows the explanation in (Korn,
2009).

in (obt,hhol1,paint,2,(from(store) $))(0.64,0.32)$ ep(paint,2,2,(paint(grey, 100/1))) $\rightarrow$

(1)ap(paint,3,3,(paint(obtained))) $(0.64,0.32)$ $\mathrm{cf}=1 \times(\min (64,1), \min (.32,1))$ ap(paint,3,3,(paint(obtained)) $)(0.64,0.32) \rightarrow$ (1)in(check,paint,3,hhol,1,(fed(back)) $)(0.64,0.32)$ in $($ check,paint,3,hhol,1,(fed(back) $))(0.64,0.32) \rightarrow$ (1)ap(hhol,4,4,(awar(paint)) $)(0.64,0.32)$ $\operatorname{ap}($ hhol,4,4,(awar(paint)) $)(0.64,0.32) \rightarrow$ (1)in(prep,hhol,4,brush,5,(for(paint)))(0.64,0.32) in(prep,hhol,4,brush,5,(for(paint)))(0.64,0.32) ep(brush,5,5,(qual(hard, 80/0.8,soft, 50/0.6))) $\rightarrow$ (0.7)ap(brush, 6,6,(prep(paint)) $)(0.45,0.42,0.22,0.22)$

$\mathrm{cf}=.7 \mathrm{x}(\min (.64, .8), \min (.64, .6), \min (.32, .8)$, $\min (.32, .6))=.45, .42, .22, .22$

where the certainty factors of 'ap' are calculated by taking all combinations of certainty factors of 'in' and 'ep' and using the minimum of each term to be multiplied by 0.7 , the certainty factor of the rule (Korn, 2009, Durkin, 1994]. The same way as is done for the 'dp' statement and can be 
written as

$$
.7 \times\left(\begin{array}{ll}
\min \text { (prepared .64 hard brush .8) } \\
\min \text { (prepared .64 } & \text { soft brush .6) } \\
\min \text { (prepared .32 hard brush .8) } \\
\min \text { (prepared .32 } & \text { soft brush .6) }
\end{array}\right)=\begin{array}{r}
.45 \\
.42 \\
.22 \\
.22
\end{array}
$$

ap(brush,6,6,(prep(paint))) $(0.45,0.42,0.22,0.22) \rightarrow$

(1)in(check,brush,6,hhol,4,(fed(back)))(0.45,0.42,0.22, $0.22)$

in (check,brush, 6, hhol, $4,($ fed(back $)))(0.45,0.42,0.22,0.2$

2) $\rightarrow$

(1)ap(hhol,7,7,(ready(paint))) $(0.45,0.42,0.22,0.22)$ ap(hhol,7,7,(ready(paint)) $)(0.45,0.42,0.22,0.22) \rightarrow$

(1)in(paint,hhol7,fence, 8 , (paint(byhand))) $(0.45,0.42,0.2$

$2,0.22)$

in(paint,hhol7,fence, $8,($ paint(byhand) $))(0.45,0.42,0.22,0$

$.22) \wedge \operatorname{ep}($ fence $, 8,8,($ qual(rousurf, $100 / 1))) \rightarrow$

(1) ap(fence, $9,9,($ painted(byhand))

$(0.45,0.42,0.22,0.22)$
For causal chain 2.

dp(hhol,10,10,(awar(product,100/1)) $\rightarrow$

(1)in(con,hhol,1,hhol,1,(imp(paintedfence)))(1)

in (con,hhol,1,hhol,1,(imp(paintedfence)) )(1)

(1)ap(hhol,11,11,(cons(impression)))

The dotted, directed lines carry the time it takes for a change of state to take place.

Ordered pairs corresponding to components of the product are written as

At: $a p(3,3) n_{3,20}=[\operatorname{ep}(2,2)]$ paint (obtained from) $(1 /$ store $)$ $(.64, .32)$

At : $\operatorname{ap}(6,6) \mathrm{n}_{6,6}=[\mathrm{ep}(5,5)]$ brush (prepared for [painting]) $(.45, .42, .22, .22)$

Using eq.4.13. in (Korn, 2016), the ordered pairs in words in Figure 7. and the linguistic network in Figure 8., are:

From $n_{3,20}=$ grey paint [related to] is obtained from the local store

From $\mathrm{n}_{6,6}=$ hard or soft brush [related to] is prepared for painting

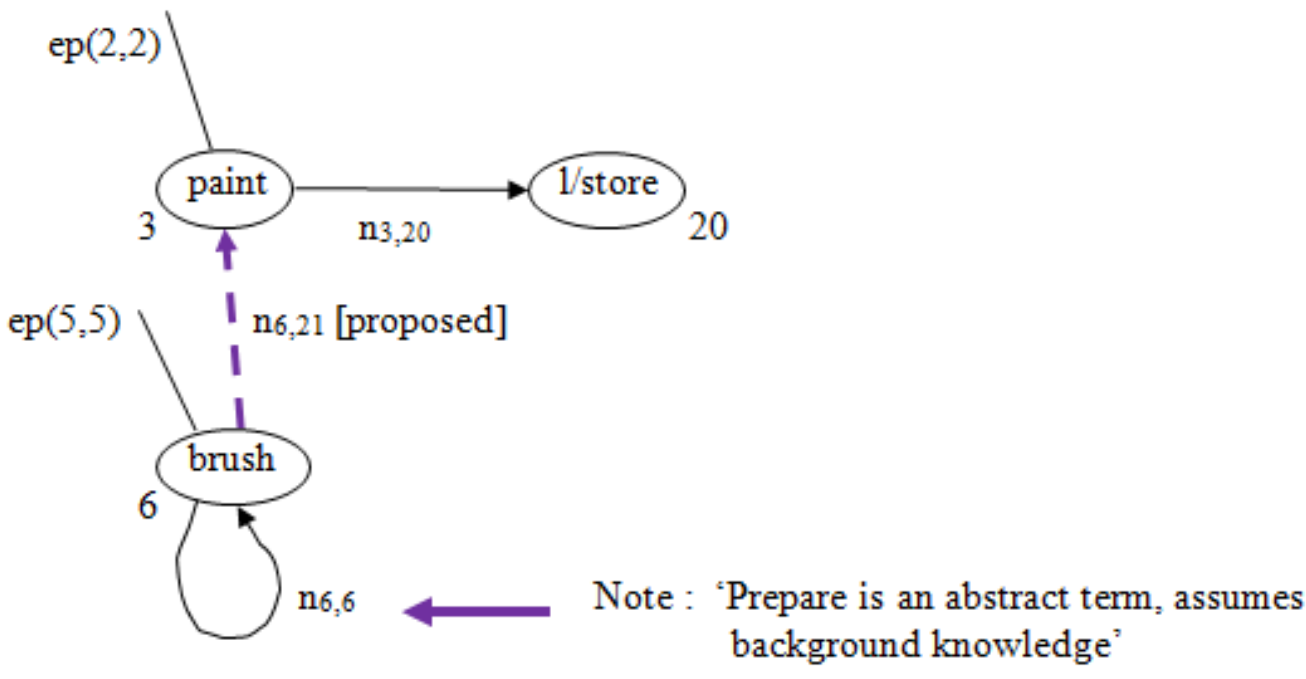

Figure 8. Linguistic network of ordered pairs of product 


\section{Remarks}

1. The linguistic network in Figure 8. is disjointed, therefore, it cannot be put forward as a 'product'. However,

$\mathrm{n}_{6,21}=$ 'Brush is dipped in paint, objects 6-3' makes the network connected. It becomes a 'product': Connection of paint to brush was missing (Korn, 2018).

We note: The accomplishment of the 'acquired property, (ap)' for generating this ordered pair requires an additional 'system' in the diagram of Figure 7.

2. Using the verbal equivalents of certainty factors as listed in Figure 4.3. in (Korn, 2009, Durkin, 1994), we can say for objects 3 and 6

$\mathrm{n}_{3,20}=$ Grey paint is obtained [64: probably] or [32: less than may be] from the local store

$\mathrm{n}_{6,6}=$ Brush is prepared for painting [from calculations attached to 'ap(brush, $6,6, \ldots .$. ', hard brush [45: may be prepared] or soft brush [42: may be prepared] or hard brush [22: unknown] or soft brush [22: unknown]

The variation of certainty of the 'problematic issue' to be resolved at object 9 in Figure 7. is as follows

$\mathrm{n}_{9,22}=$ Fence painted by hand in good order $[45 \ldots .22$ : varies from 'may be' to 'unknown']

which tells us that 'enhancement of visual appearance of the property' is subject to uncertainty which varies from 'probably and may be' to 'less than may be and unknown'.

This is what object 10 in Figure 7. the 'householder' perceives through ' $\mathrm{dp}(10,10)$ ' property.

The uncertainty arises from the activities depicted in Figure 7. being prone to adverse characteristics expressed by adjectival and adverbial phrases attached to objects or agents. Figure 7. should also show ways and means of how to improve the performance of the scenario.

We can say that the semantic diagram in Figure 7. carries the structure of the scenario through objects or agents and interactions, the topology of the scenario, on which properties or characteristics or features of agents are superimposed. Structural aspects are the matter of systems science, the question of characteristics and their relations is a matter for aspects of conventional science together called the scientific enterprise.

3. The certainty factors alongside the acquired properties at objects 3, 6, 9 in Figure 7. produce a number of scenarios depending on the selection of a sequence of cf. The total number of sequences is $2 \times 4$ x $4=32$ the certainty of which varies from:

$.64 \rightarrow .45 \rightarrow .45$ when multiplied $=.13$ to $.32 \rightarrow .22$ $\rightarrow .22$ when multiplied $=.0155$

which says that the production of the product is highly uncertain if the uncertainty of all acquired properties is taken into account.
4. The dynamics of production in Figure 7. shows the 'algorithm' or sequence of production :

'Paint has been obtained from the store' then 'Brush is prepared for painting' then 'Fence is painted by hand'. The first two acquired properties are the components of the product.

\section{Variation of product}

From a linguistic network using the expression for combination (Durell, 1959, Korn, 2018)

$$
\mathrm{N}(\mathrm{N}-1) \mathrm{C}_{(\mathrm{N}-1)}=[(\mathrm{N}(\mathrm{N}-1)-0)(\mathrm{N}(\mathrm{N}-1)-1)(\mathrm{N}(\mathrm{N}-1)-
$$
2)....]/[1 $23 \ldots(n-1) !]$ exp.1.

in which the number of terms in the nominator is ' $\mathrm{N}-1$ ' divided by ' $\mathrm{N}-1$ ' factorials. For example, when ' $\mathrm{N}=3$ ', we have ${ }_{6} \mathrm{C}_{2}=(6 \times 5) /(1 \times 2)=15$. This number shows all the possible variations of the topology or configuation of the product : more than one such configuration could be 'feasible'.

6. We note that the scheme in Figure 7. is a particular case of that in Figure 2. supporting the idea of universality of the latter. Also, the scheme in Figure 2. introduces the notion of 'problematic issue' being carried by an OPI and the resolution of a problem at User/utiliser depends on the favourable change of state of this object.

7. Figure 7. is a rigorous form of Figure 2., it caters for the idea of accepting an outcome only if it satisfies an 'expectation' by a living thing as the resolution of a 'problematic issue'.

Note: This section follows the example given in 'Application of linguistic modelling in systems and product design'.

\section{Criteria for a Symbolic Structure to be 'Scientific'}

Speculative thinking for the expression of opinions, views, beliefs etc. in terms of natural language is prevalent by people in every day and professional life. Precision is not required, there is no time and need. However, when it comes to generating symbolic models for implementation of thinking concerning issues A., B. and C. in section 'Evolution of a view of the world' a formal model is needed. People have a propensity for generating such models but not all of them may be seen suitable for this use (Beer, 1979, Checkland, 1982]. Only models capable of producing 'scientific' or testable outcomes are accepted i.e. those which can be refuted against experience (Popper, 1972). Accordingly, criteria are needed to filter out those which cannot be called 'scientific' and a suggestion towards this end is described. 


\section{Symbolic structure $=$ Model}

In general, the concept of 'model' is described as: 'Theoretically we can make an infinite number of declarative statements about any part of the world or empirical object all of which are hypothetical. Thus, complete knowledge is impossible to attain. In practice we are satisfied with one or a few statements selected by interest or a point of view of an observer or analyst. Consistent statements can be organised into a structure of symbols which may be seen to constitute a static or dynamic representation of a scenario or a 'model' of an aspect of a part of the world'.

The function of a model is representation and communication with meaning encoded in a medium to affect the appropriate sense organ of a receiver. In empirical science a model can be used for assessment of the truth value of a hypothetical statement or a principle. Thus, a particular case can invalidate a general principle [Magee, 1985, Korn, 2018].

\section{$1^{\text {st }}$ Criterion:}

\section{Structural Characteristics ---}

The $1^{\text {st }}$ General Principle of Systems states that the 'Systemic or structural view of the world is pervasive, empirical, indivisible and hierarchical' (Korn, 2018). There is an increasing level of complexity which has been constructed by natural evolution or by man in the form of one level of complexity nesting in the next level as seen, for example, by Mendeleyev's 'periodic table of elements'. The practical appreciation of this kind of structure and the corresponding model of one of its instances needs to have the following features:

\section{A. Elementary constituents}

A model consists of 'elementary constituents' which can evolve over centuries, like the atomic view, and are regarded as the building blocks of a symbolic structure at a specific level of complexity. For example,

In chemistry,

protons, neutrons, electrons comprise ----- atoms [Hydrogen $=$ proton + electron $]$

atoms comprise ----- compounds $\left[\mathrm{H}_{2} \mathrm{O}=\right.$ hydrogen + oxygen)

compounds comprise ----- mixtures [dough $=\mathrm{H}_{2} \mathrm{O}+$ flour + salt] .

In network theory of engineering systems (Korn, 2012), properties + variables comprise ----- network element network elements comprise ----- network networks comprise ----- complex object complex objects comprise ----- organisation.

In the 'New Science of Systems' (Korn, 2018), the elementary constituents are modelled by ' 1 - and 2 - place sentences' of natural language attracting one or two nouns respectively which represent the simplest form of the 'subject - predicate' construction capable of conveying 'complete meaning' of a scenario (Burton, 1984). They are used for constructing 'semantic diagrams' as shown in Figure 7. All of which show the nesting feature of structures.

In current systems thinking (Jackson, 2000, Korn, 2019), no exhibition of elementary constituents is explicitly attempted.

\section{B. Generation of complex structures}

There is a method for constructing a variety of 'complex structures' from simple ones, a version of the $2^{\text {nd }}$ General Principle of Systems (Korn, 2018) which is described as:

'Beginning with elementary constituents appropriate at a given level of complexity, construction goes on to ensure inclusion of a new property which is such as to enable the resulting assembly or whole to be connected to another towards forming the next level of complexity. This process goes on until a desired product or achievement or an emergent property is recognised which is capable of producing an 'outcome' (Checkland, 1982, Korn, 2018)'.

For example, geometrical properties [length and width] and material properties [wood] combine ---- into 'legs of a bed' [with a screw joint at one end, the new property] which are joined to a 'framed mattress' [with a screw joint at one end, the new property] and 'head board' towards forming a structure which is recognised as a 'bed', the desired product.

\section{Remarks}

1. In Figure 2. this construction is carried out by agents in contours 1., 2. and 3. at an operational level until the static structure of a product is reached and represented by a 'Cartesian product' of 'ordered pairs' with stative verbs to stand for relations which produce 'linguistic networks' as shown in Figure 8., for example (Korn, 2009).

2. Construction of structures of abstract, symbolic, imaginary and emotive aspects of a part of the world proceeds along similar lines with 'interpretation' playing a significant role.

C. Translation of story language into model language and vice versa

Natural language is the primary model for symbolic representation of an aspect of a chosen part of the world, which can be comprehensible and meaningful for all who speak the language. It is usually possible to relate its terms to any concrete, abstract, symbolic, imaginary or emotive part of the world.

In general, we suggest that the large variety of models or symbolic structures originate from natural language, the primary model. A particular model is invented because its informative content is easier and more efficient to interpret 
or the expressive power intended by its creator is easier to deliver such as a sculpture, or it offers more precise predictions such as a mathematical model than that of natural language. Interpretation of the content of natural language is a serial matter whereas that of a painting is done as a whole at an instant. A 'road sign' is a good example of this aspect of understanding parts of the world. The starting point in modelling a part of the world in 'linguistic modelling' is a 'story in natural language' which is directly transformed into 'formal language' which can be manipulated as considered in section 'Operational form of Figure 2.' and is shown in Figure 9.

The problem in general is to match general cases into particular cases and vice versa or expressing 'model language' in 'story language' or interpretation or to fit one into the other. The method of accomplishment of this is based on the:
1. Recognition that the terms in 'model language' are more general or embracing or have a wider meaning than those in a 'story language' because a model must be applicable to a range of particular scenarios each is described in terms of 'story language',

2. Identification of a term in 'model language with that in story language' and vice versa by seeing that the latter is contained in the former (Saeed, 1997). The means of seeing is through 'identity' and/or 'function'. For example,

A term in model language $=$ Floor coverings

Terms in story language $=$ Layer of sand, carpet, lino, hardboard, tiles and so on

where all story terms are particular cases of the model term. All terms signify objects which can be used for 'covering floors' or performing the same function.

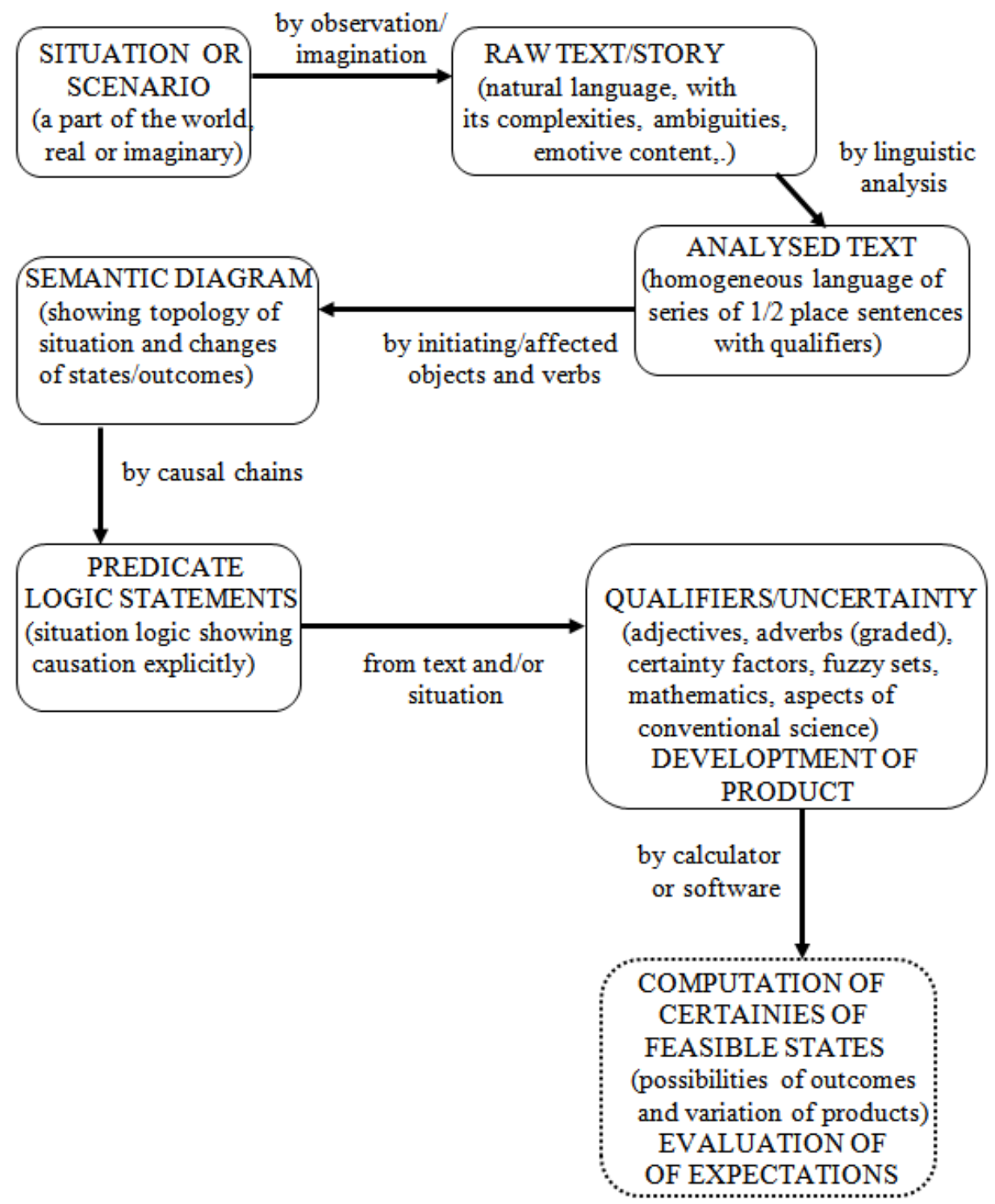

Figure 9. Scheme of linguistic modelling of scenarios 
In the scheme in Figure 2., the function of the terms can be read off the diagram or the function of an object in a contour is defined by its position in the diagram. For example, the function of the 'product' which is a term in model language is 'to change the initial into final state of OPI'. A particular instance of the term 'product' can be identified, for example, as an 'energy converter' (story language) which can be made more concrete towards an 'operational model' when named as 'electric motor' or 'candle' (story language) which all fit the term 'product'. 'Shoe lace' also fits 'product' but it does not fit 'energy converter', it functions as a 'converter of an open shoe into a laced shoe'. The notion described can be summed up by

A term in model language $\geq$ A term in story language $\exp 2$.

Similar considerations apply to the interpretation of verb phrases representing interactions.

\section{$2^{\text {nd }}$ Criterion:}

\section{Logical Conditional ---}

Any statement to be 'scientific' must be testable against experience. A statement is hypothetical in the first instance, not yet tested. The scheme for testing is realised by the expression of the logical conditional which is the formalisation of an instance of every day practice in communication by people (Copi, 1978):

'If there is a statement (antecedent) and the statement is subjected to some kind of a specific input condition or a stimulus then there is a corresponding, output or outcome condition (consequent)'.

The output condition or consequent is testable if the statement in the antecedent of the conditional is constructed from elementary constituents which can be related to experience according to point $\mathrm{C}$. of the $1^{\text {st }}$ criterion or can be reconstructed or observed in practice and is seen to be subjected to an appropriate input. This is the condition for a 'linguistic model' to be complete i.e. a linguistic model is so constructed as to become 'testable', otherwise any 'story' of real or imaginary events can be turned into a linguistic model by following the procedure indicated in Figure 9.

If the outcome of the consequent of the conditional corresponds to the observed state of affairs or turns out to be true then the statements in the antecedent have not been falsified, they have been confirmed and the conditional is true. Once a conditional is confirmed, it can be used for 'prediction' of its consequent in circumstances judged to be similar since the statements in the antecedent can be reconstructed in practice and when subjected to an input the output takes place as expected or predicted.

\section{$3^{\text {rd }}$ Criterion:}

Manipulability of Model ---

People, and some animals, construct models using symbolic structures. The intention is to prepare representations of aspects of a variety of real or imaginary scenarios fuelled by inspiration, intuition etc. for input to the sense organs, only in case of representation of a real scenario, for transmission to the brain/mind apparatus for processing with the objective of:

A. To plan activities, to create knowledge, to speculate, to prepare designs [products of the visual and performing arts, prototypes ...] which are static models,

B. To cause pleasure and emotions, to transmit information or to predict events [scientific models, problem solving] which are dynamic models.

Static models are prepared and presented to individuals to expect a response of approval or otherwise as a result of their intended outcome. Dynamic models are prepared and manipulated in order to produce an outcome which can be a 'prediction of an event' or the resolution of a 'problematic issue'.

Any symbolism can be manipulated to achieve different outcomes using their 'elementary constituents' provided these can be identified in a given situation. For example, a number of matchsticks put together to form squares [elementary constituents] can be arrange in a number of different ways.

In the so-called exact sciences, mathematical models are preferred because of their precision and possibility because of their feature of capability of being manipulated. Although their application is restricted to quantitative aspects of a part of the world. Spoken, natural language is widely applicable and as such can cope with the generality of the systemic/structural view of the world and applicable to all aspects of a part of the world. However, to become capable of being manipulated, it has to be transformed into a form suitable for manipulation by linguistic modelling as shown in Figure 9. and seen in the example in section 'Operational form of Figure 2'.

In particular, there are three kinds of 'manipulation':

1. Models which produce outcomes by solutions obtained according to rules,

Mathematical models such as algebraic and differential equations,

2. Models which produce outcomes as a result of simulation subject to input or stimulus,

Transfer functions of classical control theory (Brown, Campbell, 1948, Nise, 2008) or linguistic models such as that shown in Figure 7. which propagate state in response to input,

\section{Models for problem solving,}

The scheme in Figure 2. may be used to produce suggestions for satisfaction of expectations of a User/utiliser by varying the properties and/or structure of a 
prototype model of contours 1, 2 and 3 .

\section{Conclusions}

Consideration of section 'Evolutionary view of the world' shows that there is a pair of underlying concepts of 'producers' and 'products' which pervade throughout this view of the world. Products or achievements are created by producers driven by chance or accident in the inanimate world and by purpose, chance or accident in the animate world so as to produce the products to facilitate transformation from one state of equilibrium to another. This is called the process of 'natural evolution' or 'evolution of the artificial' (Simon, 1996).

Practically, the whole of human intellectual endeavour as indicated in Figure 1. has been directed at understanding the product, physical and intellectual, through its properties. Only in the last 70 years or so organised analysis and synthesis kind of approaches have appeared aiming at development of understanding the producer or system or structure. This effort has resulted in:

1x. Lack of depth, fragmentation and speculative discussions (Korn, 2019),

2x. Attempts but no achievement of a general systems theory (Rousseau, 2017),

$3 \mathrm{x}$. Fragmented thinking of problem solving and design (Korn, 2020).

The innate ability of the living, including humans, in engaging in production activity, since their very survival depends on it, has compensated for the latter's inadequate understanding yet so successful engagement in the producer processes of creating the world of artificial.

The incomplete understanding of aspects of existence, producers, product and change of equilibrium, have been causing confusion in thinking about the structural nature of parts of the world, in systems and product design and creating problems in teaching, especially in engineering (Anon., 1983, Checkland, 1982, Korn, 1994, 1996) which is the 'problematic issue'. The intention of current work is to attempt to remedy this state of affairs by the creation of a 'creative, scientific enterprise' for integration of social and conventional sciences and systems and conventional engineering within the framework of systems science (Lewin, 1981). This effort is open for debate.

To achieve the intention, an introduction of the $3^{\text {rd }}$ paradigm change of the 'New Science of Systems' is proposed and its location in a historical context is indicated in Figure 1. The shortcomings of the $1^{\text {st }}$ and $2^{\text {nd }}$ paradigm changes indicated in contours 4, 7, 8a, 11,12,13 as far as a general systems or structural theory aiding problem solving or design thinking is concerned, are described in (Korn, $2009,2018,2019)$. The awareness of these as indicated by points 1x., 2x. and $3 \mathrm{x}$. above, has prompted the development of a 'New Science of Systems' which is outlined in this paper.
The systems phenomenon is a universal, empirical phenomenon in the natural and artificial worlds. The phenomenon is interpreted as interacting [in dynamic state] or related [in static state] qualified, concrete, abstract, symbolic, imaginary [fairy tale] or emotive objects or 'agents'. This view is met by the 'New Science of Systems' consisting of three general principles and 'linguistic modelling' which can result in operational description of scenarios to expose the principles to the possibility of falsification (Popper, 1972, Korn, 2018). The procedure of creation of a linguistic model is shown in Figure 9. and by the example in section 'Operational form of Figure 2.'

The role of Market and 'problematic issue' in Figures 2. and 3. has been placed in context of 'problem solving'. The criteria for a model to be seen a 'scientific' has not been applied. The 'New Science of Systems' is rooted in accepted branches of knowledge such as linguistics, logic etc., it is eminently teachable, introduces linguistics to supplement mathematics as a symbolism in teaching and can influence thinking of people in social situations. Development of the 'New Science of Systems' may affect disciplines like chemistry and nuclear physics due to their being concerned with related parts. However, further peer review, debate, practical applications, software development and further theoretical scrutiny are needed.

\section{REFERENCES}

[1] Anon., The Finniston Report, Engineering our future, HMSO, London, 1983.

[2] Beer, S., The heart of enterprise, Wiley, Chichester, 1979.

[3] Bertalanffy von, L., An outline of general systems theory, The British J for the Philosophy of Science, v1, n2, 134-165, 1950.

[4] Blackett, P. M. S., Operational research, Advanced Science, v5, n17, 1948.

[5] Brown, G., Campbell, D., P. Principles of servomechanisms, Wiley, NY, Chapman \& Hall, London, 1948.

[6] Burton, S. H., Mastering English Grammar, Macmillan, London, 1984.

[7] Checkland, P., Systems thinking, systems practice, Wiley, Chichester, 1982.

[8] Copi, I. M., Introduction to logic, Macmillan, NY, 1978.

[9] Durell, C. U., Advanced algebra, G. Bell \& Sons, London, UK, 1959.

[10] Durkin, J., Expert systems, Macmillan, NY, 1994.

[11] Jackson, M. C., Systems approaches to management, Kluwer Academic, NY, 2000.

[12] Kineman, J. J., Relational science: A synthesis, Axiomathes, v21, issue 3, 393-437, 2011.

[13] Klir, G. J., An approach to general systems theory, Van 
Nostrand, Reinhold, NY, 1969.

[14] Korn, J., Fundamental problems in engineering degree courses, European $\mathrm{J}$ of Engineering Education, v19, n2, 1994.

[15] Korn, J., Domain-independent design theory, J of Engineering Design, v7, n3, 1996.

[16] Korn, J., Science and design of systems, Troubadour Pub., Leicester, UK, 2009.

[17] Korn, J., Network modelling of engineering systems, Troubadour Pub., Leicester, UK, 2012.

[18] Korn, J., Linguistic modelling of scenarios, Troubadour Pub., Leicester, UK, 2013.

[19] Korn, J., The purpose of change is problem solving, Troubadour Pub., Leicester, UK, 2016.

[20] Korn, J., General principles of systems, Kybernetes, v47, n8, 2018.

[21] Korn, J., Crisis in systems thinking, Kybernetes, Earlycites, 2019, 10.1108/K-01-2019-0026.

[22] Korn, J., Application of linguistic modelling to systems and product design, I J of Markets and Business Systems, v4, n1, 2020.

[23] Kuhn, Th., The structure of scientific revolutions, U of
Chicago, Pa., USA, 1996.

[24] Levene, L., I think, therefore, I am, M. O’Mara Books, London, 2010.

[25] Lewin, D., Engineering philosophy-the third culture, Proc of the Royal Soc of Arts, v129, n5, 1981.

[26] Magee, B., Popper, Fontana Press, London, 1985.

[27] Maturana, H. R., Varela, F. J., Autopoiesis and cognition: Realisation of the living, Reidel Pub, Dordrecht, 1980.

[28] Nise, N. S., Control systems engineering, Wiley, Chichester, UK, 2008.

[29] Popper, K., The logic of scientific discovery, Hutchinson, London, 1972.

[30] Rittel, H. W., Webber, M. M. Dilemmas in a general theory of planning, Policy Sciences, v4, 155-169, 1973.

[31] Rousseau, D., Systems research and the quest for scientific systems principles, Systems, n5, 1-16, 2017.

[32] Lewin, D., Engineering philosophy-the $3^{\text {rd }}$ culture, Proc of the Royal Soc of Arts, v129, n5, 653-666, 1981.

[33] Saeed, J. I., Semantics, Blackwell Publishers, Oxford, UK, 1998.

[34] Simon, H., A., The science of the artificial, MIT Press, 1996. 